\title{
What Future Do We Want For Science and Technology Foresight?*
}

\section{by Luk Van Langenhove, United Nations University, UNU/CRIS (Comparative Regio- nal Integration Studies), Brugge, Belgium}

The article discusses some of the deficits marking the current situation of European Foresight going on to propose measures for their remedy. Several measures have already been adopted by the European Commission in its Sixth Framework Programme for Research and Development.

In the report "Thinking, debating and shaping the future. Foresight for Europe" of the STRATA High Level Expert Group (HLEG) of the European Commission chaired by the author, it has been stressed that Foresight is gaining importance due to accelerated social and technological changes. Also, a case was made for developing an open co-ordination between Foresight activities in Europe. The development of a Knowledge Sharing Platform was proposed as an intellectual infrastructure to support the development of a European-wide foresight community (see Box 1, next page, containing the recommendations of the HLEG to the European Commission). The 6th Framework Programme has taken up this recommendation and there are good hopes that such a Platform will be established (see the article by Werner Wobbe in this issue).

This paper focuses on the contextual issues related to this development and discusses some major problems (in SWOT terminology, one could speak of "weaknesses" and "threats") and some possible futures ("opportunities" and "strengths") for Science and Technology Foresight in Europe.

The current state is marked by three major trends in Science and Technology Foresight shaping its situation in Europe:

1. There has been a definite move away from forecasting towards futures studies.

2. There is an emerging institutionalisation of the Science and Technology Foresight community in Europe, not least thanks to the efforts of the European Commission; the annual conferences organised by the Presidencies are a step in the right direction. The work of the Technology Foresight Unit (K2) in DG Research, and of the Institute for Prospective Technological Studies (IPTS) is also encouraging. The Knowledge Sharing Platform could be the incubator of this trend. The challenge is to realise this platform employing the open coordination method and not in a centralised way.

3. Science and Technology Foresight has a spatial dimension. There is a growing tendency to link the practice of Science and Technology Foresight to meaningful entities such as regions.

These trends are promising as they pave the way for a European Foresight Area in support of the emerging European Research Area. However, there are still major problems that could well jeopardise the future of Science and Technology Foresight in Europe:

$>$ While the idea of Science and Technology Foresight is to contribute to the improvement of political decision making processes, practice teaches us that the impact of Science and Technology Foresight on science policy is in many cases still very limited;

$>$ There is the impression that many Science and Technology Foresights give too much emphasis to technological developments instead of focussing on societal trends and issues. There is a strong case to start Science and Technology Foresight from societal problems and not from technological developments;

> Science and Technology Foresight is at the end of the day a social sciences practice and the quality of Science and Technology Foresight could be significantly improved if alliances were developed with relevant social sciences communities.

Finally, Science and Technology Foresight in Europe needs to pay attention to three issues in order to overcome the above mentioned problems:

1. The participative element in science and technology policy: in order to overcome the democratic deficit in that policy, expertise built up by the TA community needs to be exported to the field of Science and Tech 
nology Foresight. The organisation of Science and Technology Foresight offers unique opportunities for bridging the gaps between citizens and decision-makers and between experts and laypeople.

2. Societal developments: a key element of Europe are our diverse but unique social welfare systems. In each of the European countries exist mechanisms for guaranteeing social justice at national level. Health care, pensions, education, they are all organised at a national level. But the European integration and the globalisation are putting severe stress on those systems and we will have to think about what social welfare at European level we want in the future. The Treaty of Amsterdam has identified four societal objectives for Europe (developing a sound economy, protecting heath, maintaining an increasingly vulnerable environment and providing security against external threats). Science and Technology policy needs closer links to these objectives. The ultimate question is what kind of future is there for the European models of the welfare state? And what can science and technology contribute?

3. Global aspects both at a European and a global level: the downward scaling of Science and Technology Foresight from national levels to regional levels is to be applauded, but there is also upward scaling necessary. There is need for global Science and Technology Foresight where Europe is considered as one macro-region amongst others. This will allow both the framing of science and technology policy in the context of global problems and in the context of the competition between the "triad" USA, Japan and Europe.

In line with the so-called "Washington consensus", the USA has developed a "competitive

\section{Box 1: Recommendations of the STRATA High Level Expert Group to the European Commission}

\section{Foresight activities at a European level:}

1. Two broad strands of activities should be developed at the European level:

$>$ activities to tackle European-wide issues;

$>$ the development of open co-operation between Foresight activities implemented at the various levels in Europe.

2. Foresight should be encouraged through a series of targeted projects, based on appropriate issues that are inherently transborder and/or particularly complex. These projects should involve key stakeholders in an open and interactive process.

3. A Knowledge Sharing Platform should be developed as an intellectual infrastructure for experience-sharing and discussions. It could allow actors to benefit from the diversity of their activities and should provide services to support the development of a European-wide foresight community.

4. Evaluation instruments for assessing the quality of foresights in Europe need to be developed.

\section{Short term recommendations to the Commission:}

5. The European Commission should undertake a feasibility study on the establishment of a Knowledge Sharing Platform to be set up during the 6th Framework Programme.

6. With regard to the 6th Framework Programme, it is recommended to the Commission that:

A sufficient number of targeted Foresight projects on European Futures should be initiated.

Networks of excellence on Foresight in Europe should be supported under FP6.

An infrastructural support service for cross-connecting regional or transborder foresight projects should be set up.

Source: STRATA HLEG on Foresight, "Thinking, debating and shaping the future: Foresight for Europe", Brussels 2002, p. 15. The full text of the report is available on the Internet at:

$\mathrm{ftp}: / / \mathrm{ftp}$. cordis.lu/pub/foresight/docs/for_hleg_final_report_en.pdf 
approach" to trade liberalisation in which regional trade agreements are seen as competing with multilateral approaches to market opening. Europe is following as the EU now negotiates as a region with other regional entities. Obviously, the EU as a regional actor in a global trade play needs a co-ordinated science and technology vision and policy. Hence, foresight at a European level is needed in order to mobilize the European Research Area in the global competition game. Next to global economic governance, there is also a growing need to tackle the global problems such as climate change, AIDS, ... For this science and technology need to be mobilised. As those problems are by definition not limited to national boundaries, such efforts need to be organised at a higher level. The U.N. are playing an important role in this, but it looks like that there is a specific place for organizing global responses to global problems at the level of macroregions such as Europe: that level being high enough to formulate relevant responses but not too high in order to be inefficient. Hence: foresight is needed at a European level in the context of mobilizing the European science and technology potential for combating global problems.

All of the above makes me conclude that there is a need to complement the national and regional foresights with foresight exercises at a European level. There is probably widespread agreement that Science and Technology Foresights can contribute to identifying possible futures, imagining desirable futures and defining strategies. In line with the complex multilevel governance system that exists in Europe, this needs to be organised at all relevant levels and the challenge is to think how to organize a "multi-level European Foresight". As Science and Technology Foresight is itself a scientific practice, there is no reason not to use foresight in shaping the future of Science and Technology Foresight. Therefore, the time is ripe perhaps to organise a foresight on the future of foresight in Europe!

* This is an edited version of the author's written contribution to the recent conference on Foresight in Ioannina (Greece): Foresight in the Enlarged European Research and Innovation Area, May 14 - 16, 2003; see report on page $63 \mathrm{ff}$. in this issue)

\section{Contact}

Professor Dr. Luk Van Langenhove

Director

United Nations University - Comparative Regional Integration Studies (UNU/CRIS)

c/o College of Europe

Dijver 11, B - 8000 Brugge, Belgium

Tel. +3250477511

Fax +3250447510

e-mail: lvanlangenhove@cris.unu.edu 